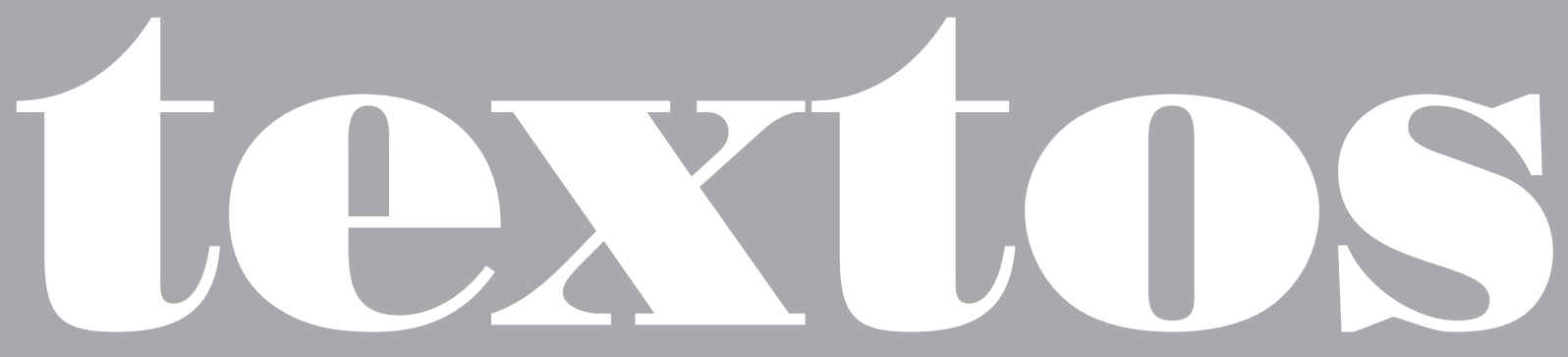





\title{
A sociedade disruptiva - fazendo das máquinas, humanos e dos humanos, máquinas
}

\author{
Alvair Silveira Torres Junior
}

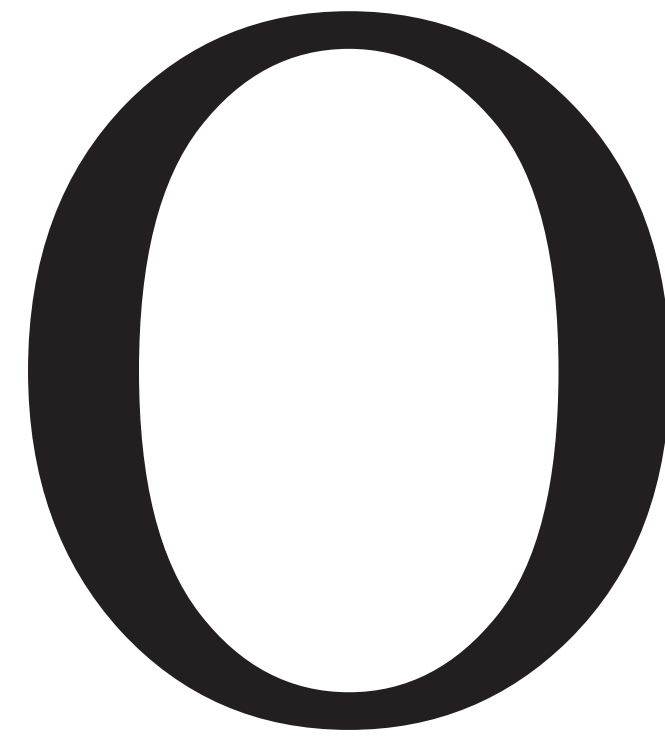

presente artigo se insere na tradição do gênero de ensaio em ciências humanas. Nele se pretende discutir alguns aspectos sociais e políticos vinculados ao modo como se tem disseminado na população as mudanças tecnológicas em curso. Como está sendo socialmente construída a aceitação das novas tecnologias e suas implicações políticas (Berger \& Luckmann, 2011), em especial aquelas ligadas com a adoção das bases digitais, robótica e IA (inteligência artificial). Com maior liberdade no trato das contribuições de 
outras ciências, como cabe ao texto ensaístico, o artigo pretende contribuir sobre como as narrativas das mudanças tecnológicas têm sido elaboradas no senso comum, e como o relativo distanciamento da população em relação ao que se discute na universidade pode ter graves consequências nas políticas sociais e nas representações políticas.

Tem surgido a figura da tecnologia humanizada, com ou sem robôs, o que nos faz questionar qual a sua ética e suas relações com os humanos.

Não há dúvidas quanto aos avanços em capacidade produtiva e de utilidade que as inovações tecnológicas ao longo do tempo propiciaram ao homem no que diz respeito a resolver problemas da vida (Landes, 1994). Ainda mais com os atuais programas e máquinas de grande capacidade de processamento das informações - big data - envolvendo uma quantidade de dados muito além dos limites do cérebro humano. Medicina, engenharia, direito, educação, comunicação, empresas, enfim, grande número de áreas e locais tem sido impactado positivamente quanto à qualidade e rapidez na solução de problemas e são exemplos notórios e acompanhados pela população em geral. Portanto, não há o que discutir aqui sobre essa ampliação nas possibilidades de se resolver problemas, fato que deve ser preservado e estimulado. Entretanto, tal perspectiva técnica tem produzido uma euforia mercadológica que, do lado social, prescinde de validações quanto às suas aplicações e articulações com a realidade da pólis, de tal sorte que políticas públicas sejam discutidas para ampliar os efeitos positivos, mas também evitar ou mitigar os negativos como se deve no âmbito de um projeto civilizatório.

O fato mais notório é o impacto sobre o emprego. A adoção da IA, por exemplo, tem suscitado pesquisas sobre quais as reduções de ocupações que seriam produzidas em diferentes economias na medida da sua disseminação no mundo do trabalho. Os prognósticos variam de $40 \%$ a $60 \%$ de redução de carga de trabalho para os humanos, impactando inclusive funções que exigem habilitação universitária (Nedelkoska \& Quintini, 2018). Médicos radiologistas não precisam mais procurar por sinais brancos nas chapas reveladas, sistemas automatizados processam as imagens, identificam os sinais e soltam diagnósticos. Claro que essa realidade ainda é diferente quanto aos países e ao tipo de serviço. No Brasil o serviço público é majoritário quanto ao modo de chapas reveladas no lugar das imagens digitais. Para a população mais pobre tal fato é um atraso, com despesas correntes maiores e falhas de diagnóstico mais frequentes. Contadores e advogados já devem se preparar para enfrentar os sistemas que emitem demonstrativos e petições automáticas. Bastará assinar... Por enquanto. Trabalhadores em linhas de montagem são substituídos por sistemas robotizados integrados com outros sistemas digitais na chamada indústria 4.0 provocando a diminuição gradativa da necessidade de operários.

Evidentemente há um apelo da eficiência, qualidade e segurança nesses e noutros casos. A questão é que tais sistemas são pensados majoritariamente em substituição ao humano, quando poderiam ser pensados junto a uma solução social e política de convívio: friendly automation or friendly robotic. Que alternativa haveria para continuar com os benefícios técnicos da automação cognitiva e das rotinas, sem levar as ocupações de médicos, engenheiros, advogados e operários à extinção ou redução? Há por outro lado um discurso 
otimista ou utópico sobre a solução social através da criação de outras ocupações. Muito se fala, em contraposição ao alerta social, que outras ocupações serão criadas. Economistas citam externalidades negativas cuja semântica já nos aponta para algo externo, periférico, de fora. Não se deixa claro como será resolvida a lacuna empregatícia. Acredita-se que o mercado arranjará uma solução e muitos apelam para a metáfora evolucionista, como já apontamos em artigo anterior (Torres Jr., 2019). Outros dizem que o empreendedorismo é a solução na criação de ocupações e que devemos nos preparar para tal realidade. Porém não se mede o quanto esse mercado sem renda ou sem financiamento poderá dar vazão a tantos empreendedores fora das empresas focais, nem se lembram de contar o sem-número de startups em incubadoras, aceleradoras, em hábitats de inovação ou por conta própria, que buscam aportes do sistema tradicional e muito poucos são escolhidos. Outros correm por fora, mas a mortalidade é alta. Haja criatividade. Haveria capacidade de absorção? Já tivemos um experimento nesse sentido. A área de serviços recebeu boa parte da massa de trabalhadores deslocados por ocasião da onda de automação microeletrônica nos anos 80 e 90, acompanhada da reestruturação produtiva em cadeias globais. A precarização acompanhou esse processo na medida em que ocupações de qualidade na indústria foram perdidas sem compensação na mesma proporção no setor de serviços (Kon, 2015, pp. 438-45), principalmente nos países de baixa e de média renda.

Do lado ético e da precaução com os perigos biológicos sobre a vida das pessoas, temos a notícia sobre o andamento das pesquisas da empresa Neuralink, de Elon Musk, com chips implantados em cérebros de ratos, suscitando no mercado o alvoroço das possibilidades de uma aplicação médica controlada evoluir para a criação de um $c y$ borg, ampliando a capacidade cerebral dos humanos (Financial Times, 19 de julho de 2019). A singularidade homem-máquina com a gradual extinção do humano na forma como hoje conhecemos nossa espécie pode se tornar realidade na linha do que Kurzweil (2006) defende sobre sua perspectiva da imortalidade. Outros, mais cautelosos, como o pioneiro da era digital, Bill Gates, clamam por regulações para que o tal mercado não avance o sinal não só com os implantes neuronais, como também nas aplicações de IA e robótica. Afinal tais tecnologias e seus avanços apresentam um tamanho potencial de impacto social sobre a vida das pessoas que de fato poderiam ser alçadas ao tipo de desenvolvimento com o mesmo cuidado ou similar ao das políticas regulatórias praticadas no desenvolvimento de medicamentos, com células-tronco e outras questões biológicas. Não se trata de restringir a pesquisa, mas de agir com seletividade sobre quais descobertas devem evoluir e como evoluir para aplicações no mercado.

Do lado da representação política, as chamadas fake news prosperam em ilusões e induções sobre os cidadãos. A imagem de quem posta incessantemente nas redes sociais de forma política escamoteia em certa medida essa intenção de luta pelo poder, levanta a falsa imagem de um não político ou de um político moderno, quando de fato pouco ou nada o afasta da chamada velha política, a qual nem é velha ou nova, simplesmente é política. As mídias sociais passam a se constituir em uma nova cobertura do conteúdo e a população tem seu voto influenciado pela imagem digital, cujas tecnologias ganham 
em poder na criação de realidades virtuais dos candidatos e dos fatos (Morozov, 2018, pp. 138-42). Passa-se a votar em imagens construídas virtualmente, de grande poder de envolvimento e deslumbramento emocional (Han, 2018, pp. 59-68), criando-se um outro mundo em que o indivíduo passa a exercer sua expressão política, cuja ágora curiosamente se distancia da realidade concreta da vida, com ela opondo-se em contradições materiais, as quais, no entanto, não causam dissonância cognitiva. Pobres, por exemplo, passam a defender pautas desmobilizadoras de políticas sociais protetivas.

Desde quando a arte, através da pintura e da literatura, passou a retratar como tema a vida dos trabalhadores nos romances e quadros, em compasso com as mudanças propiciadas pela modernidade, o maquinismo e a automação surgiram ora como alvo de crítica, ora como objeto enaltecido em um mundo em transformação. A robótica e a transformação digital repetem esse movimento nas hostes culturais, contudo há algo de novo: as próprias tecnologias agora são intimamente ligadas com a criação de narrativas, trazendo de forma intrínseca a comunicação, a liberdade de produzir e disseminar mensagens, em um movimento que ilude com a pretensa emancipação do indivíduo.

No início do século XX no Brasil, Tarsila do Amaral reproduziu em certa fase de sua trajetória pictórica, durante o chamado movimento antropofágico, representações de um Modernismo eufórico, retratando eletrificações, máquinas, bondes, em paisagens coloridas. Havia ali, entretanto, ausência do retrato das pessoas do povo. Curiosamente, como que havia naqueles quadros um prognóstico inconsciente de que tudo aquilo não reverteria em modernidade para a maioria da população. De fato, passada a modernidade e agora em tempos de pós-modernidade, não alcançamos na mesma medida avanços em aspectos sociais de trabalho e renda. É preciso, portanto, cuidado com as narrativas utópicas que atingem o senso comum.

\section{SOCIEDADE DISRUPTIVA - INTEGRAÇÃO E FLEXIBILIDADE DE HOMENS E MÁQUINAS NAS ORGANIZAÇÕES}

Não é preciso ficar com aquela tecnologia nascente dos anos 20 para resgatar as euforias declinantes. Nos anos 80 e 90, a chamada automação microeletrônica (AME) também privilegiou os progressos produtivos e em menor medida os sociais. Nela, com a inserção da possibilidade de programação das máquinas, os primeiros robôs surgiram focados na substituição do humano em trabalhos repetitivos e perigosos. Essa primeira onda tecnológica da robótica, ainda praticada em grande parte nas organizações industriais, era focada sobre os movimentos repetitivos integrando-os em um só corpo mecatrônico dotado de flexibilidade, através da programação realizada em linguagem computacional pelo homem (Torres Jr., 1994). Agora, com a IA, a programação é feita através da própria máquina emulando o cérebro humano. Essa automação cognitiva muda o conceito de aplicação da automação e passamos a pensar robôs equivalentes às capacidades humanas no planejamento de atividades (Ford, 2016).

A humanização da máquina leva ao extremo o paradigma da integração homem e máquinas, de tal sorte que há uma segunda onda robótica dotada de inteligência artificial em que não há mais proteção física separando os dois corpos - homem e ro- 
bô (Ford, 2016). Já convivemos no mesmo espaço com essas máquinas em uma nova arquitetura de convívio entre dois mundos, social e técnico. Um novo patamar de integração e flexibilidade é alcançado com amplo leque de possibilidades na conexão dos dois mundos. Esse imbricamento sociotécnico de máquina e humano impacta de outra forma as instituições. Os modelos sociais são agora mediados por máquinas dotadas de IA e o convencimento não se dá apenas por culturas eminentemente humanas, mas também por interações com redes, em culturas virtuais, produzidas por homens e máquinas.

O agrupamento de robôs e máquinas comunicando-se entre si gera comunidades robóticas, realidade nas práticas da indústria 4.0 e seu braço da internet das coisas (IoT). Assim como os aglomerados de bactérias em comunicação vital originaram os corpos macroscópicos autônomos com seus códigos genéticos de regulação, a evolução dos centros de serviços e trabalhos tecnológicos autônomos exigirá algoritmos dotados de direitos e deveres robóticos para a regulação dessas comunidades. Na natureza a regulação foi dada pela seleção natural. E no novo mundo sociotécnico? Como e quem fará tal empreitada? As leis de Asimov claramente não são suficientes.

Portanto, as atuais narrativas sobre novas tecnologias e suas relações sociais, econômicas e políticas, sobretudo as digitais e a robótica com IA, carecem de uma discussão quanto aos seus impactos na formação do senso comum. Da sua aparente neutralidade técnica ou de suas perspectivas entusiasmadas, passando por resistentes de primeira hora, as narrativas sobre os impactos da tecnologia no cotidiano das pessoas podem carregar para o senso comum do cidadão a armadilha de não levar em conta a necessidade de considerar e discutir políticas públicas para tratar de seus mais diversos aspectos.

Políticas públicas que eventualmente não considerem o potencial de mecanização das relações sociais, assim provocadas pelas novas tecnologias instauradas em espécies de algoritmos sociais, podem levar o mercado ao risco social de adotar dado viés nos pressupostos dos algoritmos reais que formam as bases de dados da IA. Na utilização do machine learning, por exemplo, os algoritmos podem vir a ser responsáveis por decisões que encaminhem grupos humanos a um dado comportamento visto como superior, sem considerar, entretanto, matizes culturais e políticas. As máquinas aprendem e os humanos em sua maioria, o chamado povo, reproduziria algoritmos estabelecidos.

Identificar e discutir tanto práticas ocultas quanto possibilidades inexploradas das novas tecnologias junto à população são uma necessidade premente, que visa a contribuir para a construção de outras narrativas, em que as novas tecnologias, sobretudo a robótica e a IA, sejam inclusivas, diversificadas e éticas, voltadas para melhorar a vida de todos.

Certos aplicativos, por exemplo, já orientam pessoas sobre comportamentos, como se o humano estivesse sendo treinado e adestrado pela máquina. Em que pese esses algoritmos serem desenvolvidos para fins úteis como saúde e educação financeira, controle de peso, dentre outras aplicações, não há uma discussão ética sobre sua exacerbação em outras frentes. Haveria a percepção da impessoalidade técnica como garantia ilusória de isenção.

Nos gadgets digitais há toda uma interação com o usuário calculada por uma engenharia de features, criando elementos que projetam e executam a chamada experiência 
do usuário, levada a cabo pela transformação digital que se faz dotando as interações com a chamada redução de atritos de humanos com humanos. Já é argumento técnico de qualidade e design moderno buscar soluções ou serviços que não precisam de interação com outro humano. Redução de atritos.

O desequilíbrio das narrativas, pendendo para o lado utópico, pode levar a externalidades negativas das tecnologias sem regulação, com o acirramento da segregação e diminuição da interação social no cotidiano, com consequências políticas e possibilidade em marcha da redução da abertura e controle por todas as camadas sociais.

\section{SOCIEDADE DISRUPTIVA, UM FENÔMENO DE MUDANÇAS MULTIDIMENSIONAIS}

Desde os tempos da Grécia Antiga, nos séculos V a IV a.C., os historiadores, tendo em elevada conta Heródoto e Tucídides, consideravam e resgatavam o modo de narrar os eventos humanos mais antigos apresentando-os como narrativas que tinham autoridade, e assim formaram o senso comum dos gregos. Se os deuses de fato existiam ou não, se aquelas histórias míticas eram reais ou não, esse já era um tema de debate; todavia o fato era que elas serviam em grande medida ao povo grego como narrativas que transmitiam ensinamentos sobre as coisas da natureza (física), o comportamento (ética) e a natureza dos deuses (teologia).

Passados os séculos entre aqueles primeiros registros das origens da civilização ocidental, com contribuições dos povos egípcios e persas, também coletadas pelos gregos, os tempos históricos foram preenchidos por narrativas ficcionais e de não ficção, em última análise com mensagens percebidas como de não ficção, estabelecendo as bases dos comportamentos e opções políticas dos agrupamentos humanos, de comunidades, nações, organizações e, agora no século XXI, em redes virtuais, influenciando as diversas esferas do cotidiano dos indivíduos em seu senso comum, que, apesar dos especialistas, são hoje a base das decisões da vida política.

Há, entretanto, substancial diferença nesse processo entre séculos exatamente no atual momento histórico; as narrativas são impulsionadas de tal maneira pela tecnologia tanto em mensagem quanto em meios, levam às novas práticas e ações, e delas se alimentam, tornando múltiplas suas origens com processos de constituição e aceitação diversos, fragmentados e multicêntricos em uma escala, se não exponencial, ao menos de grandeza muito além do registro recente, tanto que o termo "exponencial" tornou-se senso comum, e aqui, de passagem, como termo que exemplifica e evidencia pontualmente a distinta narrativa do atual Zeitgeist de uma sociedade disruptiva.

Sociedade disruptiva é o termo aqui empregado para designar este espírito dos tempos utilizando o conceito que Christensen (1997) estabeleceu no âmbito de suas pesquisas sobre inovação, nos anos 90. Ele descreveu como novidades surgem desajeitadas, de baixo desempenho, não assustando, mas com o passar do tempo superam o modelo ou padrão vigente e em seguida o destrói ou relega-o ao limbo.

Em ciências humanas, no século passado, a partir dos trabalhos de Thomas Kuhn (2018) na filosofia e na história da ciência, difundiu-se o termo "paradigma" para as mudanças sucessivas dos modelos científi- 
cos ao longo da história, e dele as ciências humanas emprestaram por décadas tal conceito para se referir, com o termo "novos paradigmas", aos fenômenos de construção social que emergiam contra paradigmas vigentes. Todavia, em que pese também agora termos uma série de fenômenos emergentes questionando e pressionando o status quo, a diferença fundamental é o papel que a tecnologia tem nas escolhas por parte dos grupos sociais, não só da técnica em si, mas no papel de construção das narrativas hegemônicas que fazem vingar nos grupos sociais e políticos certas escolhas e padrões.

A estrutura da sociedade disruptiva se estabelece a priori em três tendências narrativas, retórico-argumentativas, sobre suas possibilidades tecnológicas e guarda um quarto e pouco explorado tópico, discutido aqui na conclusão, e que viria a ser o equilíbrio social a evitar a disfunção em curso.

\section{A escala exponencial mecanizando o humano}

A escala exponencial é uma desmedida técnica sobre o humano. Não há condições de o nosso aparelho físico e biológico dar conta das múltiplas narrativas e construções sociais que circulam nas redes e emitem opiniões. Nossos processos de homeostase não são preparados para tal amplitude, restringindo-se ao $\mathrm{eu}$ e grupos mais próximos (Damásio, 2018, pp. 250-4). Antes centrada no especialista, agora a tecnologia permite a todo humano emitir e propagar suas afirmativas e construções sociais.

Como reação da nossa adaptação biológica, o cérebro adota padrões possíveis dentre infinitos para sua percepção e manu- tenção. No entorno desses padrões em circulação os agrupamentos humanos vão se constituindo como tribos identificadas com narrativas diversas, dentre squads, tribes, grupos, times, compartilhamentos, curtidas, adicionando ou deletando, sempre escolhendo e operando um determinado conjunto de comportamentos. Espelhando-se na forma de máquinas clássicas com suas especialidades e funções inscritas na natureza de suas peças e programas, também narrando uma história em execução, agora o humano tem sua identidade, seu gênero, sua ideologia, seus likes, como máquina específica que ignora outras funções, sem acesso social a outras possibilidades, restrito àquele mundo construído por narrativas específicas de opiniões, relatos, imagens, memes. Sua liberdade é restrita, presa ao mecanismo daquele nó da rede cibernética. O humano se fragmentou e se conteve como uma máquina típica das revoluções técnico-científicas dos séculos XIX e XX. E, mais do que isso, é preciso trabalhar para a rede, é preciso clicar, produzir, fazer parte, definir território e exercer sua função na rede, reproduzindo a narrativa, caso contrário esse humano será deletado ou desconstruído, desmontado. A máquina do humano precisa funcionar, se não, desaparecerá.

\section{A humanização da máquina}

Por outro lado, não haveria disrupção societal, assim como partimos do pressuposto ou hipótese aqui lançada, se a desmedida de comportamentos mecanizados na associação entre humanos não fosse acompanhada de outra mudança com relação à sua criatura, a máquina, na dialética semelhança e antagonismo na criação dela e dos diversos artefatos 
complexos que a seguem e complementam. Poderia se considerar que a mecanização do humano sempre esteve presente, na medida em que o capitalismo e a sociedade de consumo tornam tudo mercadoria, inclusive as relações. Obras ficcionais, tais como Admirável mundo novo e 1984, discutem essa distopia da desumanização e do controle social pela máquina, tendo em vista a vida do homem ser rotinizada e controlada há muito tempo. Todavia, o controle ali criticado é escancarado, autoritário e cruel, com um algoz desumano ou imitação cruel do humano, ambos transformados na marca distópica: o Grande Irmão.

Agora, entretanto, a máquina se humaniza, somos controlados e estimulados a produzir narrativas a partir de máquinas vistas em artefatos virtuais e físicos que nos estimulam, de forma alegre, participativa, convidativa e divertida, a reproduzir narrativas de empoderamento, de empreendedorismo, de buscar dada identidade, de diferenciação com subordinação ao controle de rótulos, enquanto as máquinas e seus artefatos nos apoiam, nos ajudam, auxiliam - "suportam" é o termo mais empregado. Tornam-se verdadeiros irmãos de bondade e fraternidade, portanto, inseparáveis. Deixamos de encontrar um amigo, mas consultamos insistentemente as redes sociais. O smartphone já temos como apêndice. Os que se aventurarem na crítica ao uso da técnica receberão do senso comum, às vezes travestido de especialistas, a reação irônica de desprezo por inferir que o outro não conhece, ou não sabe usar, ou que seria um excêntrico marginal e maledicente.

Fazendo das máquinas, humanos, completamos a disrupção social. Uma sociedade que não apenas mecaniza as relações humanas - sem novidades até aí, porém -, gera e multiplica continuamente relações sociais com ou através de artefatos humanizados que se tornam narrativas hegemônicas e estreitas: dr. Google, meu Face, quero tuitar, estou logado, influenciador digital, hacker, transformação digital... Siri, Bia... click!

\section{As narrativas reativas se acomodam}

Há uma acomodação crítica das narrativas sobre as mudanças tecnológicas? Alguns sinais parecem indicar que sim, sobretudo naquelas que atingem o grande público. Em reação à modernidade das grandes indústrias, com suas máquinas e instalações que alçaram os EUA nas décadas de 30 e 40 à chamada Idade de Ouro, com seu gigantismo industrial e prosperidade econômica, as artes também funcionaram como esteio das narrativas dos problemas sociais suscitados pelas mudanças técnicas e seu impacto na vida cotidiana. Regionalismos passaram a ser expressos enfatizando a frieza das tecnologias da época. O gótico americano exemplifica tal movimento, celebrando os valores das pequenas cidades do interior dos EUA. Pessoas simples no lugar de intelectuais como protagonistas foram enfatizadas pelos artistas como modo de criticar a hegemonia das bases tecnológicas da sociedade. Agora vemos Trump e movimentos políticos de extrema-direita sendo apoiados por regionalistas ou nacionalistas, porém sem críticas à tecnologia digital, ao contrário, delas fazem uso para criar seu grupo. O vilão é o outro arranjo político, sem referências ao uso social da tecnologia; ao contrário, ela é amiga, apoia, é aliada contra a vilania dos outros humanos. Ódio a eles. Não há neoluditas. Há uma acomodação das reações ao tecnológico, tanto à esquerda quanto à direita. Poucas vozes em prol de regulações sociais 
coexistem com a profusão de discursos retóricos utópicos, fazendo dessas narrativas simplórias sobre a tecnologia o tom dominante no senso comum.

Há como um consenso de como a tecnologia é bem-vinda e inexorável. Ela nos apaixona e nos ilude. Promete boas-novas. O senso crítico nas narrativas é de menor frequência. Há mais crítica no mundo especializado das ciências sociais, porém no senso comum a narrativa predominante é a do modelo empreendedor, da liberdade dada pela tecnologia, "uberizado", submetido ao amigo aplicativo, a quem agradece a oportunidade de ser empreendedor cativo do Grande Irmão. No lugar de Admirável mundo novo ou Metrópolis, nesses novos tempos é o romance Machines like me, de Ian McEwan, que nos desperta para os perigos desse mergulho acrítico nas novas tecnologias. Todavia não se reage em revolta como nos outrora romances épicos de ficção científica, se submete e se resigna.

Como emblema dessa adaptação negativa, conta-nos o psiquiatra Tamaki Saito (2018), o fenômeno dos hikikomori no Japão já alcançava em 2016 o número expressivo de 541 mil adolescentes. Trata-se de uma patologia social em que os indivíduos optam por permanecer socialmente isolados, em geral confinados em seus quartos, sem qualquer atividade laboral ou educacional, sem participação na sociedade, no máximo com relações através de games e redes sociais.

\section{CONCLUSÃO POR UMA PROPOSTA - ABRIR O OPACO}

Wisnik (2018), em obra sobre aspectos transversais da arquitetura, nos adverte sobre dois tipos de transparência: literal e fenomê- nica. A primeira, intrínseca ao material; a segunda, da ordem da percepção que é dada pelo arranjo dos elementos. $\mathrm{O}$ autor retoma os conceitos desenvolvidos por Colin Rowe e Robert Slutzky (e os amplia) da arquitetura e das artes para os fenômenos sociais, apontando para o nevoeiro fenomênico que paira sobre os acontecimentos contemporâneos. Da pouca clareza sobre o que acontece e por que acontece. Da confusão e das surpresas que assolam os viventes em tempos disruptivos. Tomando esse eixo, o que se considera ou se percebe transparente na profusão de narrativas que as novas tecnologias disseminam nas redes sociais e nas diversas conexões midiáticas está mais para o translúcido, que confunde a transparência com a opacidade, deixando entrever apenas sinais das sombras e não dos verdadeiros corpos. Não se revela, mas sugere e ilude. As narrativas que alcançam o senso comum são da ordem do pop, com sua profusão de signos cuja superficialidade nada revela das possibilidades desumanizantes e excludentes do emprego que se faz das novas tecnologias. Abrir passagens por entre essa opacidade dos dados pode ser um antídoto, através do desenho de políticas públicas que estabeleçam acompanhamento dos ganhos junto com a prevenção das perdas e danos sociais no uso das novas tecnologias. Fazer as organizações e instituições dar publicidade regular aos indicadores, utilizando-se dos mesmos meios tecnológicos de controle e acessibilidade similar aos usados em sua operação. Meios digitais de controle público e não um cipoal de interações burocráticas.

Em um segundo momento, discutir com a sociedade regulações que maximizem os ganhos de precisão e qualidade nas atividades humanas, sem esgarçar o tecido social. 
Quanto em termos de acidentes e impactos ambientais e de saúde os aplicativos de mobilidade urbana têm acarretado com suas atividades no modelo de negócios de plataformas digitais? E as condições de trabalho? Nessas, como em tantas outras aplicações tecnológicas, o balanço não está claro, tampouco há uma abertura para participação e decisão em prol da sociedade.

Todavia, a abertura da mudança tecnológica via acompanhamento institucional através de dados e fatos públicos não é o bastante. Em que pese abrir o debate para discussão de políticas públicas, a depender dos argumentos econômicos, o efeito pode se restringir a concessões mitigadoras de poder limitado. É preciso alcançar o topo da hierarquia no processo decisório em que a análise econômica impera. Corre a piada - ou seria uma verdade - que a economia é muito importante para se deixar apenas para economistas. Há uma opacidade nos assuntos econômicos. É preciso também abrir um canal de discussão e atuação na economia. Nela imperam afirmações ditas como verdades indiscutíveis, quando já se desvendou haver muito de construção social nas aplicações econômicas (Gala \& Rego, 2003). A análise econômica subordinada à economia política deve ser aberta para escolhas. Ora, a recente reforma da Previdência é um exemplo atual: a análise econômica informava quanto se deveria economizar, a economia política escolheu quanto cada agente deveria pagar, uns mais do que outros, e a retórica convenceu a sociedade. Com as mudanças tecnológicas, se o discurso utópico e acrítico continuar, resultado semelhante ocorrerá. Muita produtividade para alguns, aumento da riqueza e concentração para poucos, enquanto tantos outros, em um país de renda média-baixa e desigual, receberão mais pobreza, acompanhando crescente conjunto de remediados, contentes por ao menos reclamar nas redes sociais.

As externalidades negativas precisam ser medidas de forma focal e não acessória no discurso econômico. Medidas de perdas e danos devem ser projetadas e acompanhadas deixando claro quem está ganhando, quantos estão perdendo, os valores, e finalmente reorientando as políticas públicas e o próprio curso da economia política do Estado com vistas ao fomento de mudanças tecnológicas inclusivas.

$\mathrm{Na}$ linha das discussões de ações com propósito de superação das externalidades negativas da tecnologia, exemplificamos duas propostas de âmbito inclusivo na economia: assegurar uma renda básica, medida de natureza macroeconômica; e a automação amigável ou cooperativa, de natureza microeconômica e organizacional.

$\mathrm{Na}$ primeira, há uma série de trabalhos econômicos que precisam sair da marginalidade e entrar no mainstream das discussões políticas (Widerquist et al., 2013). Reverter uma parte da riqueza auferida com a alta produtividade das mudanças tecnológicas e redirecioná-la para o consumo, via políticas compensatórias de renda aos deslocados pela automação cognitiva. Associadas a processos de requalificação, formação de empreendedores, inserção de negócios sociais no mercado, enfim, a um conjunto de medidas possíveis que teriam implementação suportada e ganhos complementados advindos da repartição dos ganhos da produtividade. De Bill Gates, com sua sugestão de taxar o emprego da nova robótica, a Milton Friedman (1968), com a discussão do imposto de renda negativo, de visões de esquerdas aos liberais, há formatos 
em discussão que, entretanto, ainda estão à margem do Estado e suplantados por discurso de uma retórica neoliberal dos anos 70, atrasada e desatualizada com os problemas contemporâneos. Na economia também é preciso acompanhar o movimento disruptivo pelo qual passamos. A produtividade não pode ser mais medida apenas em um cercado daqueles que trabalham nas grandes corporações, mas deve ser inclusiva, colocando em seu denominador toda a população.

Em termos microeconômicos, o management se constituiu na primeira metade do século XX como instituição econômica, exercendo forte influência na coordenação daquilo que o mercado apresentava como possibilidades. Alfred Chandler, nos anos 70 , investigou como as grandes corporações norte-americanas tiveram um papel fundamental nas decisões sobre utilização dos recursos e seu direcionamento para expansão da produção, distribuição e consumo em massa (Chandler Jr., 1977). Em diálogo com o Nobel de Economia de 1978, Herbert Simon, essa perspectiva se junta ao conceito da racionalidade limitada de Simon (1982), possibilitando uma releitura das dimensões que restringem as decisões econômicas, indo além da impossibilidade técnica em adquirir e processar dados, em superação pela IA, porém, agora, com a necessidade de alçar o dano social e a viabilidade política como aspectos fundamentais nas decisões corporativas, a serem institucionalizadas em direção mais favorável ao humano.

A restrição a ser colocada e estimulada no processo decisório das corporações é que a produtividade deve ser aumentada, porém com a participação e cooperação do ser humano em algum grau. Que venham a IA, a robótica, os ganhos de qualidade com a adoção da automação cognitiva, todavia utilizadas em aplicações que preservem a colaboração com o humano. Modelos sociotécnicos de gestão com abordagens de participação e colaboração, na linha do desenvolvimento humano do lean management para exemplificar, existem e devem ser estimulados por políticas de incentivo (Torres Jr., 2010). Eles buscam os aumentos de produtividade e inovações corporativas, admitindo, porém, e até privilegiando, o emprego de automação amigável, em que o ser humano é poupado das atividades perigosas e repetitivas, passando a colaborar com a automação na coprogramação, escolhas, validações éticas e circunstanciais, de tal sorte que o autômato realiza, controla, indica e adverte, até impede decisões claras de alto dano, mas o arbítrio é do humano.

Tais caminhos colaborativos, entretanto, ganham nas narrativas atuais o adjetivo de ultrapassadas e aquém das potencialidades, quando na verdade elas seriam uma escolha organizacional que preserva o humano como agente e fonte da criatividade e símbolo a quem a tecnologia deve servir.

As narrativas são excessivamente impregnadas de verdades econômicas como se as escolhas de um grupo fossem indiscutíveis. Elas também reforçam a visão utópica das novas tecnologias em termos sociais. Transparência não é sinônimo de ética. Abertura não é sinônimo de democracia. O primeiro não revela tudo ou revela com segundas intenções. O segundo pode abrir seletivamente, ou abre até certa medida. Porém, ambos combinados e devidamente calibrados pela sociedade civil seriam um poderoso álibi contra mentiras abertas e transparentes que, disseminadas, se tornam verdades e ocultam o outro lado dos fatos. 


\section{BIBLIOGRAFIA}

BERGER, Peter L.; Luckmann, Thomas. A construção social da realidade: tratado de sociologia do conhecimento. Petrópolis, Vozes, 2011.

CHANDLER JR., Alfred D. The visible hand: the managerial revolution in American business. Cambridge, Harvard University Press, 1977.

CHRISTENSEN, Clayton M. T. The innovator's dilemma: when new technologies cause great firms to fail. Boston, Harvard Business School Press, 1997.

DAMÁSIO, Antônio. A estranha ordem das coisas - as origens biológicas dos sentimentos e da cultura. São Paulo, Companhia das Letras, 2018.

FINANCIAL TIMES. "Cyborgs: Elon Musk and the new era of neuroscience", reportagem de 19 de julho de 2019. Disponível em: www.ft.com/content/eec3bfb2-aa09-11e9b6ee-3cdf3174eb89. Acesso em: 20/7/2019.

FORD, Martin. Rise of the robots: technology and the threat of a jobless future. New York, Basic Books, 2016.

FRIEDMAN, M. "The case for a negative income tax: a view from the right", in J. H. Bunzel. Issues in American Public Policy. New Jersey, Prentice-Hall, pp. 111-20.

GALA, Paulo; REGO, José M. A história do pensamento econômico como teoria e retórica: ensaios sobre metodologia em economia. São Paulo, Editora 34, 2003.

HAN, Byung-Chul. Psicopolítica - o neoliberalismo e as novas técnicas de poder. Belo Horizonte, Ayné, 2018.

KON, Anita. Nova economia política dos serviços. São Paulo, Perspectiva/CNPq, 2015. KUHN, Thomas S. A estrutura das revoluções científicas. São Paulo, Perspectiva, 2018. KURZWEIL, Ray. The singularity is near: when humans transcend biology. New York, Penguin, 2006.

LANDES, David S. Prometeu desacorrentado: transformação tecnológica e desenvolvimento industrial na Europa Ocidental, de 1750 até os dias de hoje. Rio de Janeiro, Elsevier, 2005. MOROZOV, Evgeny. A ascensão dos dados e a morte da política. São Paulo, Ubu, 2018. NEDELKOSKA, L.; QUINTINI, G. "Automation, skills use and training", in OECD Social, Ployment and Migration Working Papers, n. 202. Paris, OECD Publishing, 2018. Disponível em: https://doi.org/10.1787/2e2f4eea-en. Acesso em: 20/5/2019.

SATO, Tamaki. Self-portrait or alienation in Tetsuya Ishida. Self-portrait of another [catálogo da exposição]. Madri, Museu Reina Sofía, 2018.

SIMON, H. A. Models of bounded rationality. Cambridge, MIT, 1982.

TORRES JR., Alvair Silveira. "Produtividade e mudanças tecnológicas - uma discussão evolucionista", in Jornal da USP, 13 de março de 2019. Disponível em: https://jornal.usp. br/artigos/produtividade-e-mudancas-tecnologicas-uma-discussao-evolucionista. . Integração e flexibilidade - o novo paradigma nas organizações. São Paulo, Alfa-Ômega, 1994.

"Lean principles creating a innovation environment", in Technology management for global economic growth. Portland, Portland State University, 2010.

WIDERQUIST, K. et al. Basic Income An Anthology of Contemporary Research. MA, Malden, Blackwell Publishing, 2013.

WISNIK, Guilherme. Dentro do nevoeiro: arquitetura, arte e tecnologia contemporâneas. São Paulo, Ubu, 2018. 